\title{
APROXIMAÇÕES EXPLORATÓRIAS SOBRE EDUCAÇÃO, EDUCAÇÃO FÍSICA E SOCIEDADE: ADVERSIDADES DE UM CURRÍCULO
}

\author{
Cristina Borges de Oliveira*
}

RESUMO

Este texto pretende elaborar uma reflexão à respeito da relação sociedade- educação - Educação Física e as adversidades de um currículo. Para tanto, vamos inicialmente contextualizar o atual momento histórico vivenciado pela sociedade humana, desvelando o desenvolvimento das teorias pedagógicas presentes na educação brasileira de um modo geral; em um segundo momento, apresentar alguns elementos acerca da adesão da Educação Física Escolar à teoria histórica-crítica da Educação, pela via da sistematização da proposta crítico-superadora. Esperamos, assim, evidenciar um "caminhar intelectual " que nos permita realizar a síntese necessária e fundamental para a compreensão da Educação e da Educação Física no Brasil.

PALAVRAS-CHAVE: Educação - Educação Física - Currículo - Sociedade.

\section{REALIDADE ATUAL}

$\mathrm{V}$ ivemos em uma sociedade que pauta seus princípios no lucro, na eficiência e na utilidade, na qual os indivíduos têm passado por um processo de coisificação, perdendo, então, suas identidades para ceder espaço às funções que exercem na sociedade. Neste final de século, especialmente, estamos vivendo a crise que se reflete nos planos ideológico, econômico, social, ético-político e educacional. Segundo Frigotto (1995), temos muita dificuldade para compreender a crise em sua essência, deixando de perceber sua perversidade, que se disfarça através de conceitos que se modificam ou assumem novos significados atuando no campo da ideologia.

A partir de uma visão crítica, fundamentada no materialismo histórico-dialético, o que seria ideologia? Podemos perceber o conceito de ideologia como uma equação matemática que modifica o

\footnotetext{
* Mestranda do Programa de Pós-Graduação FEF/Unicamp, membro do Grupo de Estudo e Pesquisa Infância e Aprendizagem/FEF-UFG
} 
resultado final de acordo com os interesses dominantes. É, portanto, a inversão da realidade social concreta para atender a interesses e necessidades da classe social que está no poder. Gramsci (apud Frigotto, 1995) afirma que este conceito de ideologia aproxima-se do que ele chama de ideologia não-orgânica ao trabalhador ou arbitrária, que termina por ajeitar, conciliar objetivos e ideais opostos, entre classes diferentes e antagônicas a fim de garantir o domínio burguês através do consentimento da classe afastada do poder.

No entanto, acompanhando o movimento histórico, existe também, enquanto contradição, o conceito de ideologia forjado a partir de interesses e necessidades das classes subjugadas. A ideologia orgânica ou historicamente necessária à classe trabalhadora está vinculada, de acordo com Gramsci (apud Frigotto, 1995), aos valores e visão de mundo da classe que não faz parte do poder. Baseada em concepções que visam diminuir e/ou suprimir as desigualdades sociais, estes sentimentos e modos de pensar e agir geram um movimento que, dialeticamente, estimula a aquisição da consciência de classe. E, também, de uma consciência da necessidade de luta por determinados objetivos que, muitas vezes, são direitos sociais que não têm sido atendidos.

Educação, moradia, saúde, lazer e trabalho são direitos sociais mínimos que devem existir para podermos exercer plenamente a cidadania, ou seja, para podermos participar ativamente das decisões sobre nosso próprio destino social com liberdade, autonomia, democracia e cooperação (Rodrigues, 1997, p. 102). Iremos destacar o direito à educação, já que é objetivo deste artigo denunciar que estamos vivenciando, no plano educacional, a materialidade histórica das relações capitalistas globalizadas. Estas, de acordo com Frigotto (1995), inspiram-se na teoria do capital humano dos anos 60-70 e buscam sua redefinição/re-significação, diante de uma nova materialidade, com a teoria da sociedade do conhecimento e da qualidade total nos anos 80-90.

Observamos que, desde que se globalizou pelo mundo, o capitalismo proporcionou a quebra do bloco soviético e mudanças sócio-políticas-econômicas nas nações socialistas e ex-socialistas, além do progressivo e crescente processo de enfraquecimento político dos Estados-nações em todo o mundo e o consequiente empobrecimento 
dos países subdesenvolvidos e de seus povos. Este processo é camuflado pela ideologia neoliberal sob a promessa de progresso e desenvolvimento para estes povos e países. A condição sine qua non para que tal desenvolvimento se dê é que estes países integrem-se ao processo de internacionalização do capital, alavancando seus sistemas produtivos com base na automação e informatização permitidas pelo avanço científico-tecnológico e com a aplicação de um amplo espectro de reformas que incluem a supressão de inúmeras conquistas históricas referentes aos direitos sociais.

Emerge, nesta arrancada neoliberal, em nível político, o enfraquecimento dos Estados-nações como peça-chave no processo de mundialização do capital. Este enfraquecimento pode ser compreendido a partir da falência/crise do Estado de Bem-Estar Social (alternativa do capitalismo no pós-guerra de 1945 e no final da Guerra Fria, cuja falência é representada pela queda do Muro de Berlim em 1989). Como reguladores da vida humana, surgem as empresas transnacionais, que possibilitam uma alta rotatividade do capital ao redor do mundo e direcionam o processo de internacionalização do capital e, com isso, uma divisão internacional do trabalho.

A internacionalização do capital, compreendida como internacionalização do processo produtivo ou reprodução ampliada do capital, envolve a internacionalização das classes sociais em suas relações de reciprocidade e antagonismos. Quando se mundializa o capital produtivo, mundializam-se as forças produtivas e as relações de produção. O processo de trabalho social é fragmentado em escala mundial (não mais no âmbito local, regional ou nacional) a partir da afluência de componentes e peças de máquinas dos mais diversos tipos, das várias regiões do mundo, sob o comando das empresas transnacionais que movimentam recursos desenvolvem alianças e estratégias, agilizando suas redes e seus circuitos informatizados de modo independente ou mesmo com total desconhecimento dos governos nacionais, de acordo com Ianni (1997, p. 46).

Continuando, Ianni $(1997$, p. 47) alerta para o fato de que "em escala cada vez maior, mundialmente, a grande empresa parece transformar nações das mais diversas categorias em pequena 
nação". Os países subdesenvolvidos, como o Brasil, estão subjugados a esta política por estarem continuamente buscando dinheiro nos organismos internacionais, devendo, então, obediência a uma cartilha que dita as reformas necessárias à ampliação e fortalecimento do capital transnacional.

Nesta perspectiva, o campo educacional também é pensado em termos de adaptação à nova ordem capitalista-neoliberal. Porém, para compreendermos a crise atual no plano educacional, é fundamental que venhamos a entender a internacionalização da crise do capitalismo real deste final de século, que apresenta como receita e remédio para todos os males - econômicos, éticos, ideológicos e educacionais - a ideologia específica do neoliberalismo. Tal orientação em nosso país tem sido assumida pelo governo Collor de Mello e, especialmente, pelo duplo mandato do presidente Fernando Henrique Cardoso.

Percebemos que é histórica e intencional a fragmentação do sistema educacional e do processo de seleção, organização e sistematização do conhecimento escolar. Savianni (1997) esclarece-nos que a orientação neoliberal caracteriza-se por "políticas educacionais claudicantes" que variam entre combinar o discurso em prol da educação para todos, reconhecer sua importância, elegê-la enquanto prioridade e, na prática social concreta, reduzir os investimentos para a área em todos os sentidos, apelar às organizações não-governamentais (ONGs) e, principalmente, estabelecer o setor privado. Transfere-se, assim, a responsabilidade do Estado pela educação pública, gratuita e de qualidade social para a ação de entidades privadas e/ou beneficentes, como se tal problemática pudesse ser resolvida sem a existência de políticas públicas comprometidas com os interesses e necessidades da classe trabalhadora.

A ideologia neoliberal, através de sua hegemonia no poder, não se compatibiliza com os interesses e necessidades da massa de trabalhadores que mantém as condições concretas para o exercício deste poder. Portanto, ela não é orgânica àquela massa humana, defendendo os interesses de uma minoria numérica e garantindo a manutenção do status quo. De que forma isto se dá? A partir de formas renovadas e reeditadas de exclusão das massas humanas, cada vez mais afastadas dos centros de decisão de seus próprios

102 Oliveira, C. B. de - Aproximações exploratórias sobre... 
destinos e do usufruto dos avanços da ciência, da cultura e da técnica. Percebe-se a formação que destaca o exercício de funções no mercado em contraposição à ampliação das possibilidades humanas. Qualidade total, autonomia, flexibilidade, formação abstrata e polivalente, participação e descentralização são expressões superestruturais de relações sociais que afetam o campo educacional e bebem na fonte da exclusão, sendo os conceitos centrais a atuarem na perspectiva da manutenção da situação vigente.

\section{AS TEORIAS DA EDUCAÇÃO E A EXPLICAÇÃO SOBRE A REALIDADE SOCIAL}

Tedesco (apud Savianni, 1997) apresenta dados sobre a situação educacional da América Latina na década de 1970. Através deles, podemos concluir que, em milhares de casos, crianças já se encontram marginalizadas, sem poder ter acesso à escola, antes mesmo de nascer. Sobre tal problemática - do analfabetismo potencial enquanto realidade concreta mundial -, podemos levantar algumas inquietações: como interpretar estes dados? Como explicálos e que posição assumem as teorias da educação acerca desta situação caótica? As diferentes posições que assumem as teorias da educação podem ser categorizadas, conforme Savianni (1997), em três grupos que explicam a função social da escola diante da marginalização e exclusão.

As teorias não-críticas entendem a educação como instrumento de equalização social, possibilitadora de inclusão social, tendo como função básica homogeneizar as idéias, reforçar os laços sociais, evitar a degradação moral e ética e oportunizar autonomia e superação da marginalidade, que é vista como um fenômeno acidental e um resultado da "incompetência" das pessoas, individualmente. A marginalidade é vista, então, como desvio social que pode e deve ser corrigido pela educação. É uma visão sincrética, superficial e fragmentada, que apreende apenas a aparência e o efeito do problema, desconsiderando o movimento, a historicidade, a contradição e a totalidade das relações que a escola mantém com a superestrutura capitalista; ou seja, desconsideram-se categorias que são inerentes à ação humana e, portanto, também à educação. 
Neste sentido, a escola é encarada como autônoma, isolada de qualquer influência, sendo compreendida a partir dela mesma. Em especial, as pedagogias tradicional, escolanovista e tecnicista concretizam a perspectiva da educação como redentora dos marginalizados e excluídos, através do entendimento de que a ausência de uma educação escolar possa ser a fonte originária da desigualdade de direitos e oportunidades. Admitem também que a educação escolar possa solucionar as problemáticas sociais da exclusão e da marginalidade social. No Brasil, as abordagens pedagógicas já citadas predominam, desde a criação do sistema nacional de ensino até meados da década de 1970, expressão mesmo das políticas antidemocráticas, das ditaduras e do atrelamento do País aos desmandos do capital estrangeiro.

Finalmente, as teorias críticas da educação buscam subsídios nas categorias gerais do materialismo histórico-dialético - movimento, contradição, totalidade, historicidade - para compreender o fenômeno educativo. Tais teorias vão configurar-se a partir das idéias marxistas que, no Brasil, aportam a partir da década de 1980, representando os anseios de um grupo de intelectuais insatisfeitos com a educação voltada para a manutenção da estrutura social que se apresenta naquele - e neste - momento histórico. É importante considerar, segundo Moreira (1995, p. 153), como os debates sobre conhecimento escolar foram influenciados pelas condições internacionais, societárias e processuais. Afunilando a reflexão sobre organização curricular, o autor destaca que a definição do currículo no Brasil, nos anos 80, portanto anterior à proposta histórico-crítica de educação, deveu-se mais aos fatores societários e processuais do que aos internacionais, como se apresenta atualmente, em função da concepção neoliberal.

Entendemos que a pedagogia histórico-crítica tem como premissa básica a transmissão e apropriação do conhecimento/conteúdo, como ponto principal do processo de escolarização. Essa valorização do conhecimento histórico acumulado gera a necessidade de constituir novas idéias sobre a Educação, idéias que comportem um currículo crítico tal que receba/atenda as adversidades culturais, étnicas e de gênero, além das de classe. Talvez seja esse o grande desafio da educação a partir de uma perspectiva crítica: contemplar essas adversidades em seu projeto político-pedagógico, na

104 Oliveira, C. B. de - Aproximações exploratórias sobre... 
organização da proposta curricular, efetivando assim a inclusão de todas as pessoas no processo educativo.

Chamamos a atenção para a discussão do conteúdo curricular, de sua utilidade e validade para os alunos das camadas mais pobres da população. Este aspecto é de crucial importância, haja vista as recentes e profundas investidas neoliberais que têm utilizado a estratégia de re-significação de conceitos (Frigotto, 1997), sendo a luta por educação para todos um exemplo típico de tal estratégia. Reportemo-nos à Política de Educação para Todos, que de acordo com a intenção explícita sugere a universalização da escolarização, o compromisso com a construção da democracia e da justiça social, além de garantir o ensino laico, gratuito e obrigatório para todas as camadas da população. No entanto, afirma Moreira (1995, p. 162):

Ao caráter técnico do processo educativo acrescenta-se o caráter sociopolítico. Realça-se além disso, a importância do conteúdo curricular. Quando os conteúdos não são relacionados à realidade familiar das crianças, diz o documento, o único produto que se obtém é má aquisição de conhecimento, o que não ajuda o aluno a alcançar melhores condições de vida e a se preparar para a prática consciente da cidadania(...). Podemos observar, então, que o folheto Educação para Todos, ao reafirmar a importância e a necessidade de alfabetizarmos as massas, elege o conteúdo curricular como o principal instrumento de tal processo.

As teorias críticas consideram que a relação educação-sociedade é uma relação de mão dupla, ou seja, a escola é influenciada pela sociedade em que se insere, porém, dialeticamente, pode também influir nesta sociedade. O referencial marxista de análise pressupõe ser a escola uma parte do todo social que com ele se (inter) relaciona, sofrendo, pois, por um lado, múltiplas determinações advindas deste todo. Neste sentido, a educação escolar reproduz o sistema político-organizacional-social, com suas visões de homem, mundo e sociedade. Esta educação tende, então, a configurar-se como espaço/tempo de manutenção e reforço à superestrutura capitalista, veiculando, através da sua ação, os valores, os comportamentos, as atitudes - enfim, a ética - do mundo capitalista.

Tal reprodução estabelece-se na seleção do conhecimento, na forma como tais conteúdo são tratados, no papel destacado aos 
professores e alunos, na organização administrativa da escola e do sistema educacional. Neste, o fracasso e evasão são alguns indicativos que julgamos expressarem a dinâmica excludente posta em prática no interior da educação escolar. Assim, é importante que, neste início de século, estejamos atentos às novas demandas populares e aos novos rumos impostos à organização social, já que elas apresentam-se distintas daquele momento em que a pedagogia histórico-crítica foi concebida. As questões relativas ao processo de re-significação de conceitos e lutas, como também aquelas referentes às diferenças de etnia e gênero, devem ser pensadas, no sentido da ampliação das possibilidades educacionais.

Entretanto, por outro lado, as teorias críticas da educação consideram ser possível e necessário desarticular dos interesses dominantes aqueles elementos que estão articulados em torno deles, mas não são inerentes à ideologia dominante, e rearticulá-los em torno dos interesses da classe que não detém o poder (Savianni, 1997, p. 10), no âmbito de uma pedagogia socialista de inspiração marxista, denominada pedagogia histórico-crítica. Esta teoria acredita que, apesar de o sistema de ensino configurar-se pela reprodução e manutenção da hegemonia capitalista, a escola é também espaço/tempo contra-hegemônico que permite a desconstrução da visão de mundo capitalista e a posterior (re)construção de uma sociedade igualitária e verdadeiramente humana.

É necessário, porém, destacar que a perspectiva apontada pela teoria histórico-crítica não cai na visão simplista de que a educação tem poderes de transformação social pela via da escolarização dos indivíduos, de que a função social da escola é pôr fim à exclusão e à marginalidade social, como advogam as teorias não-críticas. Superando tal visão com base no referencial marxista, a perspectiva em questão considera ser função da escola a transmissão/assimilação dos saberes construídos e desenvolvidos historicamente e a sua democratização para todos os povos do mundo. É à escola, enquanto instituição formalmente consolidada, que cabe a responsabilidade de tornar acessível à classe dominada o conhecimento acumulado pelo conjunto dos homens vivendo em sociedade.

$\mathrm{O}$ acesso ao saber acumulado historicamente é considerado aspecto fundamental para alavancar uma tomada de consciência da re- 
alidade social concreta por parte da classe trabalhadora, uma vez que o ser humano é visto como sujeito construtor de sua própria existência, possuindo, portanto, possibilidades históricas de transformação destas condições de vida desde que possa refletir criticamente sobre a realidade. Para tanto, os conteúdos curriculares são os conteúdos clássicos, sistematizados, metódicos, científicos, que expressam o desenvolvimento das formas de criação e de (re)construção da existência humana, em um processo sempre histórico, sendo pensados, nesta ótica, enquanto "elementos de emancipação humana e força propulsora da transformação das relações sociais"(Libâneo, 1996, p. 135).

A natureza/essência da educação é sociopolítica na medida em que pode, ou não, auxiliar os indivíduos a adquirirem consciência de seu lugar na humanização e democratização da sociedade, o que expressa a intensa ligação existente, na teoria histórico-crítica, entre saber e política. A escola é reconhecida como a instância educativa por excelência, porém, além de garantir o acesso ao saber sistematizado, deve também preocupar-se com os modos organizacionais com os quais proporciona a transmissão/assimilação do conhecimento.

A preocupação com a especificidade da educação - que diz respeito ao saber elaborado e não ao espontâneo; ao saber sistematizado e não ao fragmentado - é uma constante no delineamento da pedagogia histórico-crítica. A análise da educação realizada por esta perspectiva procura contextualizar a função e a especificidade da educação à luz dos múltiplos condicionantes que permeiam a sociedade humana e, em particular, a sociedade capitalista.

\section{A ESPECIFICIDADE DA EDUCAÇÃO FÍSICA E A FUNÇÃO SOCIAL DA ESCOLA}

Pensamos que a discussão sobre a especificidade da educação traz em si elementos importantes para a compreensão do atual momento vivenciado pela Educação Física escolar, uma área do conhecimento que, historicamente, adotou uma postura de pseudo neutralidade política e científica ao longo do processo histórico da educação brasileira. A Educação Física responde, em sua gênese e desenvolvimento, a necessidades conjunturais e estruturais colocadas pela afirmação e avanço do capital e da classe burguesa. 
Os conteúdos deste componente curricular apresentaram sempre determinações oriundas não da instituição escolar, mas das instituições médica, militar e esportiva. Em conseqüência disso, tais conteúdos apresentaram-se com a função de higienização corporal, de disciplinarização e de rendimento atlético, respectivamente (Souza Jr., 1999). O envolvimento com tais instituições (médica, militar e esportiva) levou a Educação Física Escolar ao reforço, à estereotipação de gênero e etnia, à adesão aos esforços eugênicos do Estado Novo; e, posteriormente, aos princípios da Segurança Nacional nos governos militares pós-64 e aos adestramentos físico e psicológico de soldados/trabalhadores para a guerra e para a indústria (Castelanni, 1991).

De acordo com a orientação recebida por tais instituições, o professor historicamente assume o papel de agente médico, de instrutor militar e de técnico desportivo, enquanto o aluno é visto como paciente, soldado e atleta, respectivamente. O referencial advém das ciências biológicas, assentadas na perspectiva positivista, sobressaindo a visão de um homem aistórico, apolítico, essencialmente considerado em suas peculariedades biológicas. O paradigma da aptidão física perpassa toda a ação da Educação Física escolar e mostra-se coerente com as necessidades do sistema capitalista de produção de indivíduos aptos ao trabalho industrial e à guerra, além de docilizados pela disciplina e hierarquia.

$\mathrm{O}$ que queremos expressar é que, em sua gênese e desenvolvimento histórico, a Educação Física assumiu, no interior da escola, características, conteúdos e funções variadas e, às vezes, estranhas à instituição escolar, trabalhando sempre no sentido da manutenção/reforço à superestrutura capitalista, porém pagando o alto preço de não encontrar elementos legitimadores de seu papel na educação escolar. O mero fato de a Educação Física ser considerada como "atividade", relegada a algo sem importância, a simples executora de tarefas, é um exemplo da dificuldade em legitimar-se enquanto área de conhecimento no sistema escolar brasileiro.

As discussões promovidas pela teoria histórico-crítica acerca da especificidade da educação escolar vão finalmente colocar a grande problemática da Educação Física nos anos 80: quais são os conteúdos de ensino da Educação Física? A partir de que critérios e 
requisitos os conteúdos de ensino da Educação Física podem/devem ser sistematizados? Afinal, o que caracteriza o saber/conhecimento elaborado nesta área? E avançando além das inquietações iniciais, qual deve ser o trato metodológico dado a estes saberes, na perspectiva de que eles (os conteúdos escolares) atuem enquanto elementos de emancipação humana? Que tipo de organização curricular daria conta de articular as intenções anunciadas em torno de uma formação humana crítica? E, finalmente, talvez devamos perguntar: como a Educação Física, em uma perspectiva crítico-superadora, poderá dar conta de incluir as questões relativas às diferenças de etnia e gênero, como têm-nos alertado os escritos pós-modernos? (Apple, 1997).

Souza Jr. (1999, p. 23) alerta para o fato de que não só a Educação Física, mas também todos os componentes curriculares, apresenta situações de conflito e antagonismos em relação à sua especificidade, uma vez que tais conflitos "dizem respeito às grandes polêmicas que permeiam as questões relativas ao saber escolar, sua produção e veiculação nas situações ensino-aprendizagem". Ou seja, a seleção, organização e sistematização de conteúdos de ensino referem-se à própria construção do projeto político-pedagógico da escola e à organização do trabalho pedagógico, que tem a ver com a organização da sociedade (Veiga, 1996).

Assim, evidencia-se que as situações de conflito que permeiam e determinam as questões relativas à especificidade e ao trato com o conhecimento em forma de conteúdos de ensino são referentes aos elementos de crítica à organização do trabalho pedagógico. Estes elementos são evidenciados no cotidiano das práticas pedagógicas dos diferentes componentes curriculares da escola capitalista, tais como vida escolar separada da produção material e sob gestão autoritária e alienante, fragmentação do trato com o conhecimento, organização escolar como mera simplificação do conhecimento científico diante de controles hierárquicos ( Freitas, 1995; Veiga, 1996).

A partir do exposto, podemos voltar à problemática específica da Educação Física enquanto prática pedagógica que materializa, em forma de conteúdos, seus conhecimentos sistematizados historicamente. Tais conteúdos são necessários à apreensão do desenvolvimento sócio-histórico das atividades corporais do ser humano 
e também à explicitação de seus significados objetivos. Como objeto de nossa atenção, a reflexão promovida por um coletivo de autores da Educação Física no início dos anos 90 configura-se como uma proposta que contém elementos constitutivos do conhecimento específico a ser tratado pela Educação Física escolar sob a ótica da pedagogia histórico-crítica, e que vai assumir a denominação de pedagogia crítico-superadora.

Nesta perspectiva, a Educação Física enquanto área de conhecimento trata, pedagogicamente,

de uma área (...) denominada de cultura corporal. Ela será configurada com temas ou formas de atividades, particularmente corporais (...): jogo, esporte, ginástica, dança ou outras, que constituirão seu conteúdo. O estudo desse conhecimento visa apreender a expressão corporal como linguagem. (Coletivo de Autores, 1992, p. 62)

Os saberes da cultura corporal tratados na escola expressam o sentido/significado deste conhecimento tanto para a sociedade quanto para os homens, mulheres e crianças que o praticam. Tratar este sentido/significado pressupõe ir além da mera aprendizagem técnica e tática, da simples "curtição" advinda da prática irrefletida, mas abrange a compreensão das

relações de interdependência que o jogo, esporte, ginástica e dança, ou outros temas que venham a compor um programa de Educação Física, têm com os grandes problemas sociopolíticos atuais. (Coletivo de Autores, 1992, p. 62)

Os conteúdos de ensino emergem da prática social concreta e devem servir ao aluno enquanto possibilidade histórica de apreensão da realidade social a partir de seus interesses de classe. Se cabe à escola promover a apreensão da prática social ampla, à Educação Física cabe a função de selecionar e organizar os seus conhecimentos de forma que os alunos possam apreender sua especificidade (jogo, esporte, ginástica, dança, lutas etc.) em sua gênese e desenvolvimento, levando-se em consideração os aspectos técnicos, filosóficos, antropológicos e sócio-históricos, além de atentar para as condições expressivas dos alunos e as condições

110 Oliveira, C. B. de - Aproximações exploratórias sobre... 
materiais da escola - que refletem os condicionantes impostos pelas relações de poder entre as classes (Coletivo de Autores, p. 65).

Libâneo (apud Coletivo de Autores, 1992) afirma que os conteúdos não devem ser apenas ensinados, mas é necessário que haja uma articulação entre o conteúdo e a sua significação humana e social, pondo em destaque a relevância social do conteúdo e também a sua contemporaneidade. Outro requisito fundamental ao trato com o conhecimento diz respeito à consideração das possibilidades cognitivas dos alunos enquanto sujeitos históricos, possuidores de um dado saber que deve ser confrontado com os saberes clássicos em uma relação de continuidade que permita a passagem da experiência imediata ao conhecimento sistematizado.

A proposta em questão faz uma crítica ao sistema de seriação, privilegiando a organização curricular em ciclos de escolarização básica (ensinos fundamental e médio) nos quais os conteúdos de ensino são tratados de forma espiralada, possibilitando a ampliação do quadro de referências do aluno no sentido de interpretá-los, demonstrá-los, compreendê-los, explicá-los e, finalmente, ter possibilidades de neles intervir. É importante frisar que a perspectiva crítico-superadora pretende ser um instrumento contribuidor para as necessárias transformações em nossa sociedade em um sentido amplo, democratizando as práticas da cultura corporal, em todas as suas nuances e formas, a todos os cidadãos e povos do mundo. Porém faz-se urgente refletir sobre quais são os novos desafios para a Educação Física, a partir de tal perspectiva crítico-superadora, que se afinam com o ponto de vista da classe trabalhadora e contrapõem-se ao currículo comprometido com a formação humana para o exercício das novas funções do mercado de trabalho e de suas novas exigências, tais como: qualidade total, autonomia, flexibilidade, formação abstrata e polivalente $x$ formação humana omnilateral.

Sintetizando, a Educação Física, nesta ótica, visa configurar uma reflexão pedagógica sobre

o acervo de formas de representação do mundo que o homem tem produzido no decorrer da história, exteriorizados pela expressão corporal: jogos, danças, lutas, exercícios ginásticos, esporte, malabaris- 
mo, contorcionismo, mímica e outros, que podem ser identificados como formas de representação simbólica de realidades vividas pelo homem, historicamente criadas e culturalmente desenvolvidas. (Coletivo de Autores, 1992, p. 38)

Neste sentido, é vital o desenvolvimento da noção de historicidade da cultura corporal enquanto aspecto da realidade que constituiu - e constitui - um acervo de ações em resposta a desafios, estímulos e/ou necessidades humanas. Este aspecto da realidade, materializando-se nas esferas da linguagem, do trabalho e do poder, deve ser tematizado na escola, tendo em vista a possibilidade de os alunos, enquanto sujeitos históricos, poderem construir uma identidade de classe, condição fundamental para o engajamento deliberado na luta pela transformação que tanto almejamos para a sociedade.

A proposta crítico-superadora, sistematizada em 1992, apresenta-se como pontapé inicial, e possível caminho também, para uma reflexão da Educação Física enquanto área de conhecimento escolar. Possível caminho para a democratização, porque sintetiza provisoriamente o processo histórico do desenvolvimento desta área no contexto das discussões mais amplas promovidas pela teoria histórico-crítica a respeito da função e especificidade da educação escolar, ponto de partida para a consolidação de formas progressistas e humanitárias no trato com conhecimento da cultura corporal da humanidade. Salientamos que a perspectiva em questão não se constitui como proposta acabada, e sim em construção, e nem pretende qualificar-se como a melhor alternativa no campo da Educação Física.

Neste sentido, alguns grupos de professores que se identificam com essa perspectiva teórica, desde o lançamento da proposta, têm buscado construir e consolidar formas metodológicas coerentes com as necessidades sociais e humanas da classe trabalhadora. Tais tentativas têm feito avançar o processo de legitimação da Educação Física e de seus professores no interior da escola, na medida em que, cada vez mais, desvinculam-se as aulas de Educação Física de momentos de simples compensação do trabalho intelectual exigido por outros componentes curriculares, de prática alienante e ali-

112 Oliveira, C. B. de - Aproximações exploratórias sobre... 
enada do esporte de rendimento, entre outras, e atrela-se o trabalho educativo do professor de Educação Física ao ato de refletir sobre a realidade social a partir do conhecimento da cultura corporal.

No limiar do século XXI, a Educação Física brasileira começa a buscar alternativas. É importante frisar que, também, estão em andamento outras propostas e sistematizações, capazes de colocarse na contra-hegemonia da razão instrumental capitaneada, atualmente, pelo processo de mundialização da economia e da cultura. Em um tempo histórico comandado pelo capital transnacional, como o que vivemos, as lutas por liberdade, dignidade, participação e democratização são fundamentais para o alcance de uma sociedade em que povos possam reconhecer-se como produtores da vida e, portanto, senhores do próprio destino. Mais que isso, é necessário intensificar estas lutas. Cabe a nós, educadores, intensificálas no âmbito propriamente pedagógico, na escola, na construção e aplicação dos currículos, nas salas de aula, nas quadras e pátios, recriando refletidamente formas de tratar o conhecimento, com os nossos alunos e com a cultura que permeia todo este contexto, na expectativa da consolidação de um mundo novo.

\section{ABSTRACT}

The purpose of this paper is to reflect upon the relation between society/education/ Physical Education and the curriculum adversities. For that reason, first, the actual historical moment lived by human society is contextualized in order to unveil the development of pedagogic theories present at the Brazilian education in general. Second, some elements of the adherence of Physical Education at Schools to the Historical and Critical Theory of Education are presented through the systematization of the criticalovercoming proposal. It is hoped, therefore, to make evident an "intellectual process" which allows realizing a summary for the fundamental and necessary comprehension of Education and of Physical Education in Brazil.

KEYWORDS: Education - Physical Education - Curriculum - Society.

\section{REFERÊNCIAS}

APPLE, M. W. Conhecimento oficial: a educação democrática numa era conservadora. Petrópolis, RJ: Vozes, 1997.

CASTELLANI FILHO, Lino. Educação Física no Brasil: a história que não se conta. 3. ed. Campinas, SP: Papirus, 1991. 
COLETIVO DE AUTORES. Metodologia do ensino da Educação Física. São Paulo: Cortez,1992.

FREITAS, L. C. Crítica à organização do trabalho pedagógico e da didática. Campinas, SP: Papirus, 1995.

FRIGOTTO, G. Os delírios da razão: crise do capital e metamorfose conceitual no campo educacional. In: GENTILLI, Pablo. Pedagogia da exclusão. São Paulo: Vozes, 1995. p. 77-107.

IANNI, O. Teorias da globalização. 4. ed. Rio de Janeiro: Civilização Brasileira, 1997.

LIBÂNEO, José Carlos. Pedagogia e modernidade. Infância, escola e modernidade. São Paulo: Papirus, 1996.

MOREIRA, Antônio Flávio B. Currículos e programas no Brasil. 2. ed. Campinas, SP: Papirus,1995.

SAVIANNI, D. Escola e democracia. 31. ed. Campinas, SP: Autores Associados, 1997.

SAVIANNI, D. Pedagogia histórico-crítica: primeiras aproximações. 6. ed. Campinas, SP: Autores Associados, 1997.

SOUZA JR., M. O saber e o fazer pedagógico. Recife: EDUPE, 1999.

RODRIGUES, A. T. Educação Física escolar: a cidadania negada. In: CONGRESSO BRASILEIRO DE CIÊNCIAS DO ESPORTE, 10, 1997, Goiânia. Anais... Goiânia, 1997. p. 102-108.

VEIGA, I. P. Projeto político-pedagógico da escola: uma construção possível. Campinas, SP: Papirus, 1996.

114 Oliveira, C. B. de - Aproximações exploratórias sobre... 